\title{
MEASUREMENTS OF THE EFFECTS OF SMOKE ON ACTIVE CIRCUITS
}

\author{
Tina J. Tanaka* \\ Sandia National Laboratories \\ Accident and Consequence Analysis Dept. \\ Albuquerque, NM 87185-0748
}

\begin{abstract}
Smoke has long been recognized as the most common source of fire damage to electrical equipment; however, most failures have been analyzed after the fire was out and the smoke vented. The effects caused while the smoke is still in the air have not been explored. Such effects have implications for new digital equipment being installed in nuclear reactors. The U.S. Nuclear Regulatory Commission is sponsoring work to determine the impact of smoke on digital instrumentation and control. As part of this program, Sandia National Laboratories has tested simple active circuits to determine how smoke affects them. These tests included the study of three possible failure modes on a functional board: (1) circuit bridging, (2) corrosion (metal loss), and (3) induction of stray capacitance. The performance of nine different circuits was measured continuously on bare and conformally coated boards during smoke exposures lasting 1 hour each and continued for 24 hours after the exposure started. The circuit that was most affected by smoke (100\% change in measured values) was the one most sensitive to circuit bridging. Its high impedance $(50 \mathrm{M} \Omega)$ was shorted during the exposure, but in some cases recovered after the smoke was vented. The other two failure modes, corrosion and induced stray capacitance, caused little change in the function of the circuits. The smoke permanently increased resistance of the circuit tested for corrosion, implying that the contacts were corroded. However, the change was very small $(<2 \%)$. The stray-capacitance test circuit showed very little change after a smoke exposure in either the short or long term. The results of the tests suggest that conformal coatings and type of circuit are major considerations when designing digital circuitry to be used in critical control systems.
\end{abstract}

\section{INTRODUCTION}

\subsection{Purpose of this Program}

Nuclear power plants are replacing analog instrumentation and control (I\&C) equipment with digital I\&C equipment; however, there is concern about how these new control systems will be

${ }^{*}$ This work was supported by the U.S. Nuclear Regulatory Commission and was performed at Sandia National Laboratories. Sandia is a multiprogram laboratory operated by Sandia Corporation, a Lockheed Martin Company, for the United States Department of Energy under contract DE-AC04-94AL85000. The opinions and viewpoints expressed herein are those of the authors and do not necessarily reflect the criteria, requirements, and guidelines of the USNRC. 


\section{DISCLAIMER}

This report was prepared as an account of work sponsored by an agency of the United States Government. Neither the United States Government nor any agency thereof, nor any of their employees, make any warranty, express or implied, or assumes any legal liability or responsibility for the accuracy, completeness, or usefulness of any information, apparatus, product, or process disclosed, or represents that its use would not infringe privately owned rights. Reference herein to any specific commercial product, process, or service by trade name, trademark, manufacturer, or otherwise does not necessarily constitute or imply its endorsement, recommendation, or favoring by the United States Government or any agency thereof. The views and opinions of authors expressed herein do not necessarily state or reflect those of the United States Government or any agency thereof. 


\section{DISCLAIMER}

Portions of this document may be illegible in electronic image products. Images are produced from the best available original document. 
affected by abnormal or severe environments, such as smoke from an electrical fire. ${ }^{1}$ In 1994 , the U.S. Nuclear Regulatory Commission (USNRC) initiated a program at Sandia National Laboratories (SNL) to determine the impact of smoke on advanced instrumentation and digital safety systems and to determine if smoke can cause failures in reactor safety systems. From a plant-risk perspective, short-term damage modes are most significant. Smoke is expected to cause immediate failures by circuit bridging and an increase in contact resistance, but corrosion is expected to cause long-term failures. In addition to determining possible failure modes, the USNRC is interested in threshold levels for failure and the behavior of the failed equipment.

\subsection{Background on Smoke Exposure Testing}

When this program started, there were little data on how smoke affected active electronics. Smoke damage in other industries, such as telecommunications, was serious enough to merit detailed analysis of smoke corrosivity and equipment recovery. However, except for the fullscale tests by Jacobus ${ }^{2}$ on relays, power supplies, and switches, no reports have been found in the public literature which measure the performance of electronics in smoke. Since nuclear power plants require continuous control and feedback from the reactor, the ability to salvage equipment after a fire is not adequate. Rather, the continuous safe operation of the sytems during and after a fire must be considered. Hence, it is necessary to be able to determine the real-time effects of smoke on an active digital system.

Smoke tests to determine the relative corrosivity of different materials have been developed by the military and telecommunications industry. The early studies by the Navy concentrated on the effects of smoke on structural elements in ships. ${ }^{3}$ Because of smoke corrosivity, the Navy also created standards for testing the smoke from various cable materials to measure its acidity. Cables that produced less acid were used in ships. Since many of the acidic gases are produced by halogenated compounds (i.e., chlorine and bromine), the Navy has been limiting the use of these materials on ships. Recently, the telecommunications industry and insurance companies have been most active in development of test methods. Most of these methods measure acidity of gases or metal loss. The acidity of the gases is assumed to be directly related to corrosive metal loss. Some of the standards developed for smoke corrosivity testing are ASTM D5485; IEC 60754-1, (1994-01); $;^{5}$ DIN 53436; ${ }^{6}$ and CNET(ISO/DIS 11907 part 2). ${ }^{7}$

Degradation of electronics due to smoke can be similar to degradation from air pollution. Polluted air contains many of the same ionic contaminants as smoke (i.e., chlorides and sulfates); however, the deposition rate from air pollution is much slower than from a fire. ${ }^{8}$ Ionic contaminants increase leakage currents by providing an alternative current path. In the presence of ionic contaminants, electrically biased conductors develop metallic dendridic growths that increase leakage currents. The role of ionic contaminants has been studied by those involved in studying reliability of electronics. One way to measure the effect of these contaminants is to measure the surface insulation resistance using an interdigitated comb pattern, as on IPC-B-24. ${ }^{9}$ This method is also being used for some smoke corrosivity testing. ${ }^{10}$ Higher levels of contamination lead to higher leakage currents.

All of this research was focused on long-term damage from a fire. An important parameter for the damage is the ionic contamination deposited on surfaces. Given that all analysis in the past has been based on postfire analysis, surface deposition is the only quantitative measure of smoke exposure available. These analyses do not address the increased leakage currents that may occur during a fire, which can lead to temporary malfunction of a circuit. 


\subsection{Previous Smoke Exposure Testing at SNL}

The smoke exposure testing at SNL has concentrated on the reaction of electronics during and immediately after a fire. Cable insulation was burned since it is a common fuel in nuclear power plants and is likely to cause more damage than other common materials. The first tests were carried out with the cooperation of Oak Ridge National Laboratory (ORNL) and their USNRC-sponsored program on advanced I\&C qualification and exposed active digital systems. ${ }^{11}$ These systems included a computer network linked by fiber optics (FDDI). The smoke caused temporary interruptions and retransmission of data. Since these interruptions were temporary and immediate, metal loss was not a likely failure mode. Digital systems that were tested did not contain electromechanical switches, so the temporary failures could not be due to soot coating the contacts. Therefore we assumed that a likely cause of failure was tempoary shorts caused by increased leakage currents.

Leakage currents were studied in more detail when empty component packages were biased with $5 \mathrm{Vdc}$ and the currents measured during a smoke exposure. Humidity, fuel levels, fuel mixture, suppression by $\mathrm{CO}_{2}$, and burning mode (smoldering vs. flaming) were varied to determine which fire conditions affected the leakage currents the most. The tests showed that smoke immediately reduces insulation resistance, but that the resistance may recover if the smoke is vented.

The major results found from all of these tests were that:

- Smoke increases leakage currents across biased contacts and causes shorts.

- Shorted electrical signals cause digital systems to receive faulty data and upset systems.

- The upsets cause intermittent failure of the system.

- High smoke density, high humidity, and flaming fires cause more failures than less smoke, low humidity, and smoldering fires.

- Conformal coatings and chip packages with large lead spacing can improve smoke tolerance.

\subsection{Focus of Paper}

The research reported here has focused on the impact of smoke on active circuits, rather than recovery of electronic equipment. It addresses the need of nuclear power plants to continuously monitor and control a reactor and to determine the immediate effects of smoke on equipment. All of the exposures in our experiments included real-time monitoring to determine what happens as circuits are exposed to smoke.

\section{SMOKE EXPOSURE METHODS}

Because there are no electronic qualification test standards for smoke, the method of exposure has been based on the draft smoke corrosivity standard for the radiant heat method proposed by ASTM E05.21.70. This method tests different materials and is a static smoke exposure - all of the smoke that is created is contained within an enclosure rather than being pumped through the exposure chamber as in dynamic smoke exposures. 
Table 1: Cable materials burned for smoke exposures.

\begin{tabular}{l|ll}
\hline \hline Cable name & Insulation & Jacket \\
\hline Rockbestos Firewall III & FRXLPE $^{a}$ & CSPE $^{b}$ \\
Anaconda Flameguard 1kv & EPR $^{c}$ & CSPE \\
Brand Rex XLPE & XLPE $^{d}$ & CSPE \\
Okonite Okolon & EPR & CSPE \\
Kerite HTK & CSPE & \\
Rockbestos Coax (le) & XLPE & \\
Raychem & XLPE & XLPE \\
Dekoron Dekorad & EPDM & CSPE \\
BIW & EPR & CSPE \\
Kerite FR & CSPE & \\
\hline \hline
\end{tabular}

${ }^{a}$ Fire-resistant cross-linked polyethylene

${ }^{b}$ Chlorosulfonated polyethylene

${ }^{c}$ Ethylene propylene rubber

${ }^{d}$ Cross-linked polyethylene

${ }^{e}$ Ethylene propylene diene monomer

The fuel is placed in quartz combustion chambers located underneath an exposure chamber and is heated and ignited in this chamber. The smoke rises up stainless steel chimneys to the exposure chamber containing the device under test. Two smoke exposure chambers were built-one that is the same size as the draft standard, and a larger one that could hold an entire computer. The smaller chamber is shown in Figure 1. The standard exposure time is 1 hour. The radiant heat lamps that heat the fuel are on for only 15 minutes. The smoke is vented after the 1-hour exposure, and the electronics continue to be monitored for 24 hours after the exposure starts.

The cable materials that were burned are listed in Table 1 . There are a large number of nuclear-qualified cables that are used throughout nuclear power plants. Rather than burning any one material individually, a mixture of the materials was burned because it would be more representative of the fires that may be encountered in a plant. The fuel was analyzed by Schwarzkopf Microanalytic Laboratory (Woodside, NY). The burned fuel yielded $23 \%$ ash, $1 \%$ bromide, $12.6 \%$ chloride, and $0.49 \%$ fluoride. The heat yield was $10370 \mathrm{Btu} / \mathrm{lb}\left(2.4 \times 10^{7} \mathrm{~J} / \mathrm{kg}\right)$.

This set of tests studied the effects of three possible failure modes on a functional circuit board: (1) circuit bridging, (2) corrosion of contacts, and (3) induction of stray capacitance. Stray capacitance can be induced by adding conductive surfaces near high-frequency circuits, and hence is related to circuit bridging. These failures were studied on functional boards containing circuits sensitive to these failure modes. The components on the boards were those commonly used in modern electrical circuits. The boards contained high-voltage (to study circuit bridging), high-current (to study corrosion), high-frequency (to study stray capacitance), and high-speed digital circuits. Circuit performance was measured continuously on bare and conformally coated boards during the smoke exposure and for 24 hours after the start of the exposure. The boards were also subjected to a range of smoke levels to try to determine failure thresholds. 
Table 2: Functional circuits tested and their likely failures.

\begin{tabular}{llc}
\hline Circuit & Sensitivity & Package \\
\hline High voltage low current & Alternative current leakage paths & PTH/SMT \\
High current low voltage & Increased resistance in solder joints & PTH/SMT \\
High-frequency transmission line & Coupling between transmission lines & N/A \\
High-frequency low-pass filter & Increased inductance or capacitance & PTH/SMT \\
High-speed digital & Increased pulse rise, fall, or delay times & PTH/SMT \\
\hline \hline
\end{tabular}

\section{RESULTS ON ACTIVE CIRCUITS}

Recent results include the functional circuit tests, comparison of chip technology, and the comparison of conformal coatings. The comparisons of functional circuit tests and chip technology were reported in NUREG/CR-6543. ${ }^{12}$ The comparisons of conformal coatings have been completed and will be included in a results and insights report due in 1998.

The functional circuit board tests consisted of 12 tests that compared the effect of smoke on different types of circuits. These circuits, listed in Table 2, were designed by the Low Residue Soldering Task Force at SNL to investigate different soldering manufacturing practices. Each circuit was designed to be vulnerable to a particular failure mechanism. ${ }^{13}$ The components of this circuit board include both plated-through hole (PTH) and surface-mounted (SMT) components. In general, SMT components are smaller and easier to install because there is no need to drill holes in printed circuit boards to install them. Thus, more and more digital systems are expected to contain SMT components. When reasonable, two identical circuits were built on the functional circuit board, one containing only SMT components and one containing only PTH components. The components of the two circuits had the same nominal value. Figure 2 shows the functional circuit board.

The failures observed during the smoke exposures for the circuits were:

- High voltage, low current-increase in conduction around both PTH and SMT circuits, resulting in reduced resistance measurement

- High current, low voltage--increase in resistance for SMT circuit only

- High-frequency transmission line--increase in coupling while smoke in chamber

- High-frequency low-pass filter-very little change from smoke

- High-speed digital--pulse stopped either immediately or after a few hours of exposure, but restarted.

To illustrate the effect of smoke on these circuits, Figures 4-6 plot the response of the circuits to smoke. In general, the circuits that responded the most to the smoke were the high-voltage, low-current circuits. These circuits had a high potential, $300 \mathrm{Vdc}$, across a high impedance circuit of $50 \mathrm{M} \Omega$. The measured resistance of the high-voltage low-current circuit depended on the smoke density. Figure 3 shows how the high-voltage, low-current circuit reacts to different amounts of smoke. For medium smoke density $\left(25 \mathrm{~g}\right.$ of fuel per $\left.\mathrm{m}^{3}\right)$, the measured resistance falls; but as the smoke clears by deposition and venting, the resistance returns to normal. The circuits tested with a high fuel load (50 g of fuel per $\mathrm{m}^{3}$ ) did not recover after venting. The 


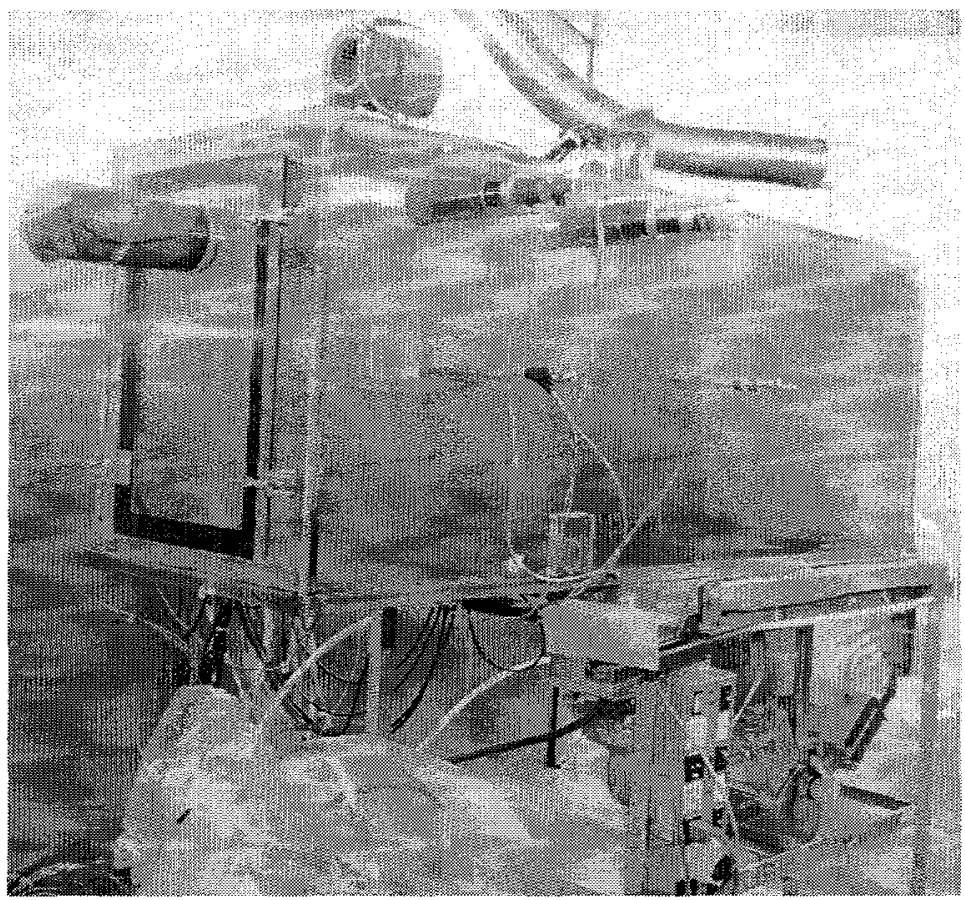

Figure 1: Smoke exposure chamber $(124 \times 470 \times 39.5 \mathrm{~cm})$.

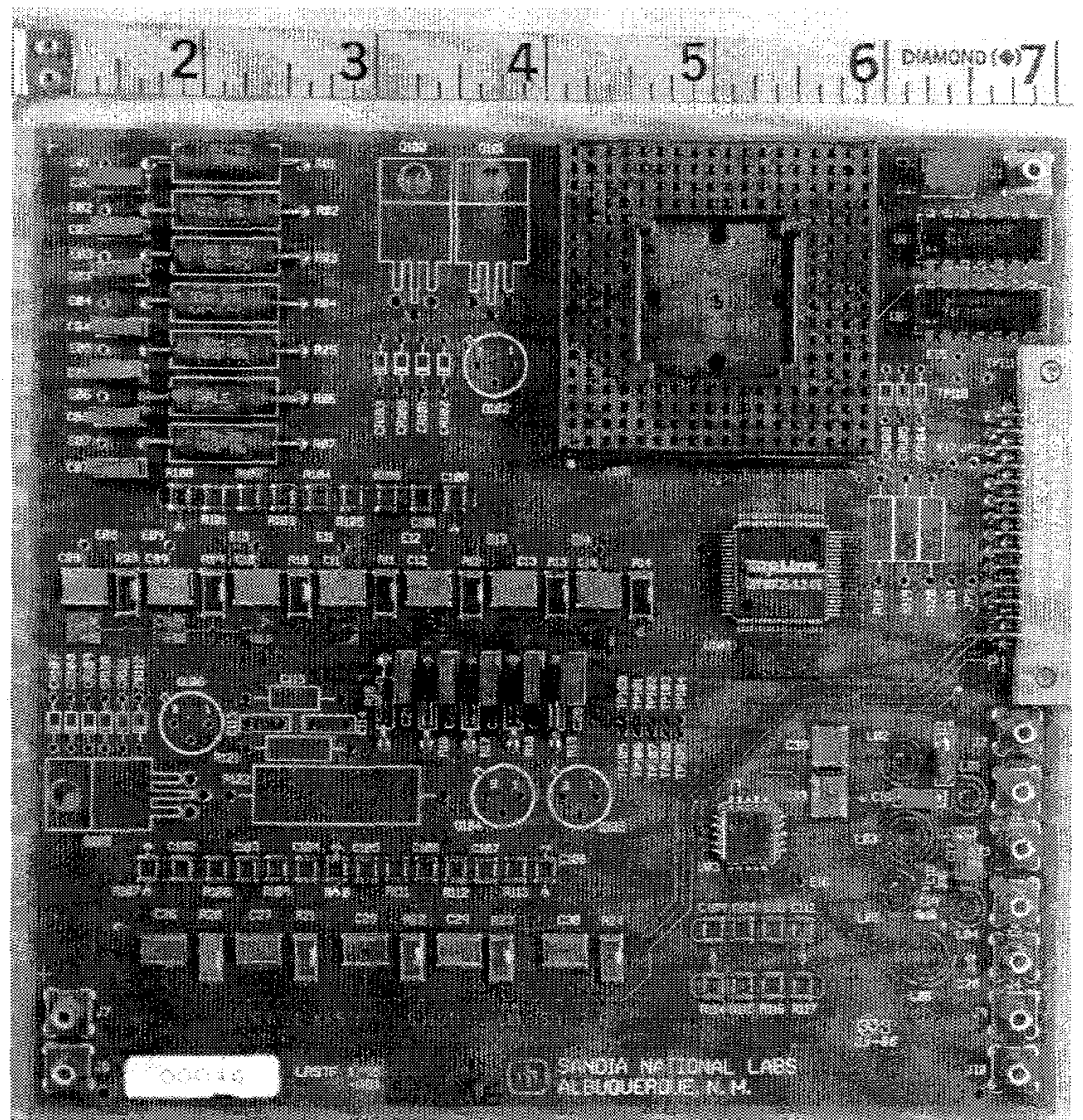

Figure 2: The functional circuit boards allowed testing for different smoke failure modes. 


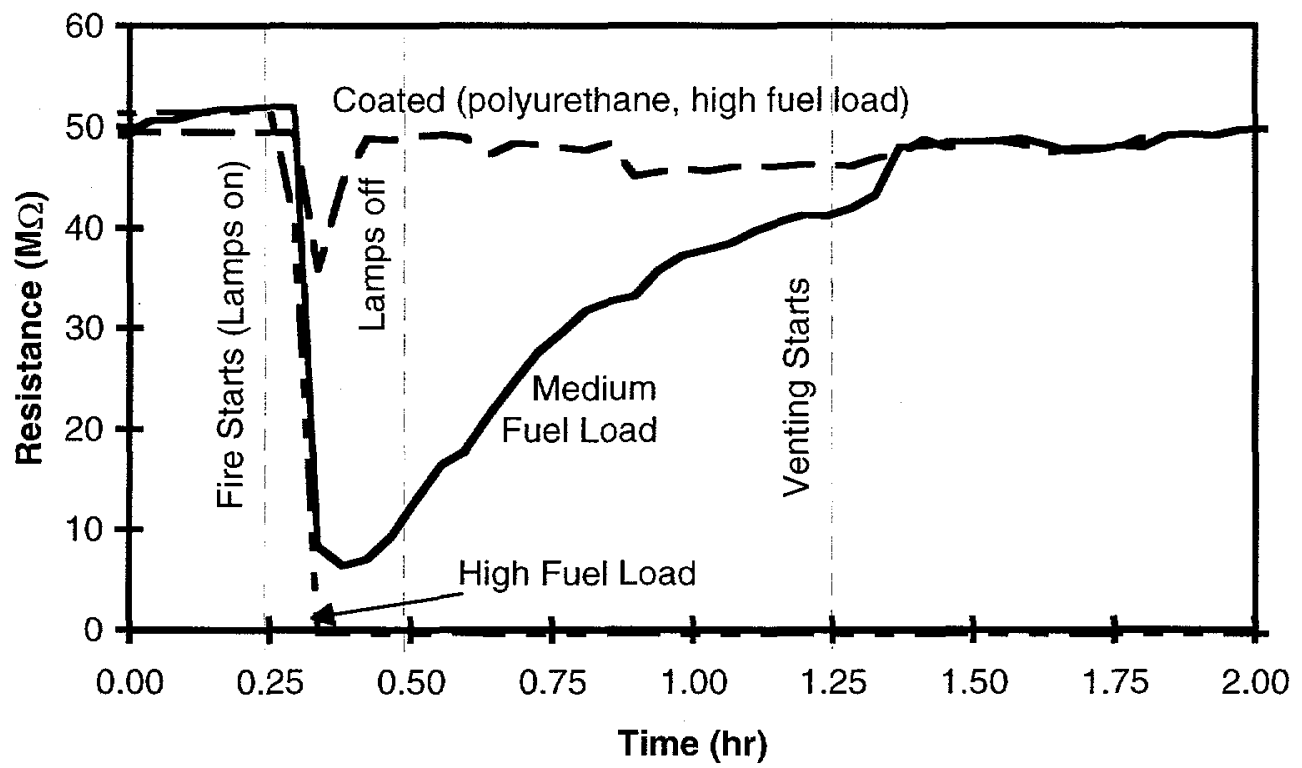

Figure 3: Increased conduction (reduced resistance) is caused by smoke particles in the air and surface deposition for the high-voltage, low-current circuit.

surface deposition was high enough that the current must have passed through the soot on the surface. The resistance of the coated high-voltage, low-current circuit did not decrease as much as either of the other circuits. A conformal coating might protect such a circuit.

The high-current, low-voltage circuit was a low-resistance circuit that was sensitive to loss of conductivity due to corrosive action of the smoke. Figure 4 shows the reaction of the highcurrent, low-voltage PTH and SMT circuits to smoke (high fuel load, $50 \mathrm{~g}$ of fuel per $\mathrm{m}^{3}$ ). The resistance of the SMT circuit increases during the smoke exposure and does not return to normal after the tests. The PTH circuit seems to be unaffected. The conductive traces or solder joints of the SMT circuit are probably attacked by smoke. Smaller amounts of smoke showed similar but less reaction. The corrosive and permanent effect of smoke is shown here by change in resistance. The change is small-only $2 \%$, even for large fuel loads.

The transmission line coupling increased at $50 \mathrm{MHz}$ as shown in Figure 5. This means that the signal transmitted by one line was picked up on a parallel line. This effect is high while the smoke is in the chamber, but diminishes once the smoke is vented. The smoke seems to act like a conductive layer between the two transmission lines.

\subsection{Coating Tests}

Conformal coatings can substantially increase the smoke tolerance of circuits. There are more than 75 conformal coatings on the market. In general, there are five types: polyurethane, epoxy, silicone, acrylic, and parylene. One coating from each of the five types was selected and applied by Specialty Coating, Inc. (Indianapolis, IN) to protect the functional boards. These coatings are listed in Table 3. The smoke exposure tests showed that all the circuits performed much better with a conformal coating, although there were minor differences in the performance of the different coatings.

The best circuit to demonstrate differences in coatings is the high-voltage, low-current circuit, because it is the most sensitive to smoke. The coatings were expected to provide quite a 


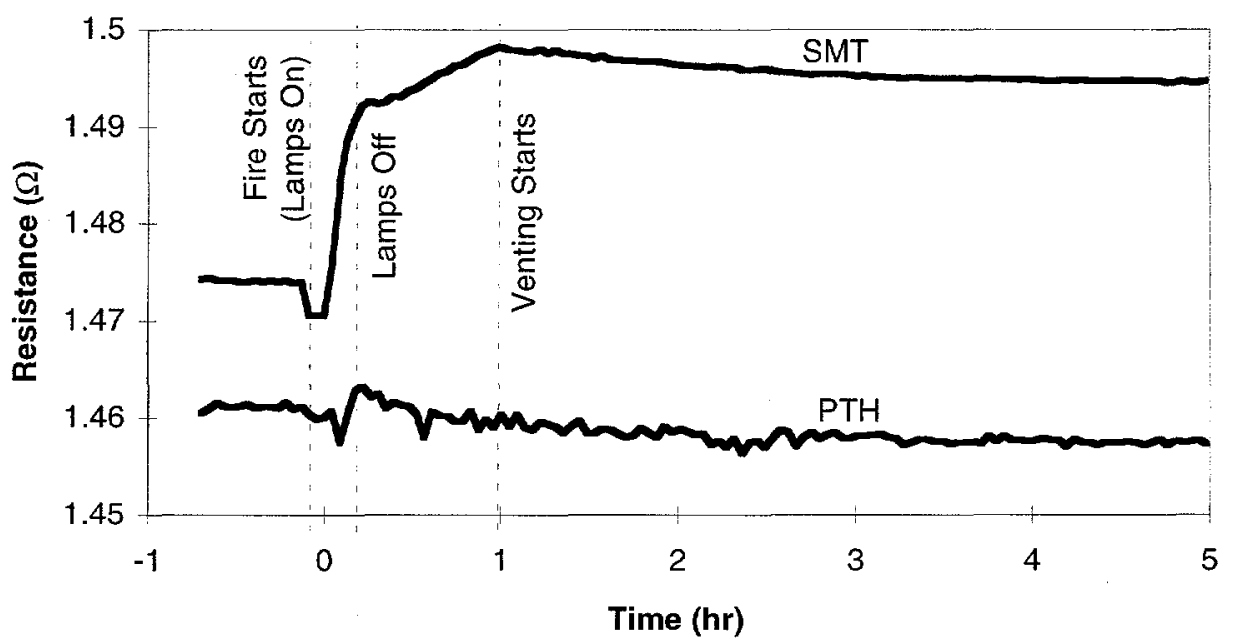

Figure 4: Smoke causes slight increases in resistance of the high-current low-voltage circuit.

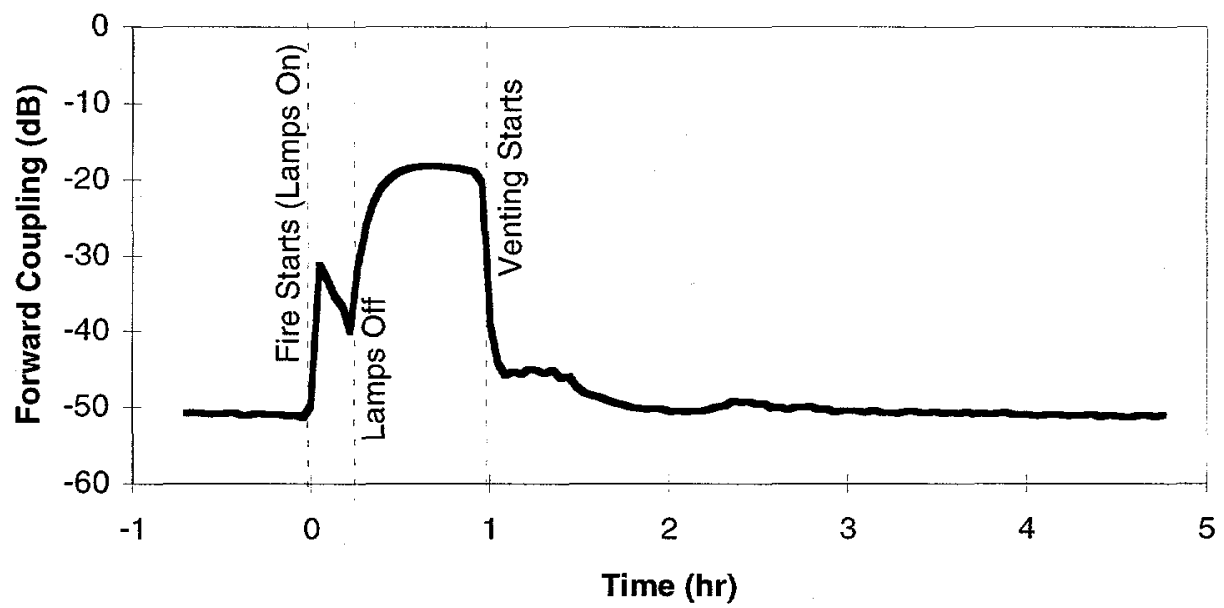

Figure 5: Smoke in the air increases transmission line coupling at $50 \mathrm{MHz}$.

bit of protection, so a very high fuel level was used $\left(200 \mathrm{~g} / \mathrm{m}^{3}\right)$. Twelve boards remained uncoated, while each of the five conformal coatings was applied to four boards (total of 20 coated boards). The data from these tests are shown in Figures 6 and 7 for the SMT and PTH circuits, respectively. The data are presented as averages of four time periods: preburn (before the fire starts), burn (during the fire), soak (after the fire is out, but before venting), and vent (during venting).

The SMT circuit reacted as expected for the bare boards, as shown in Figure 6. The pretest values were about $50 \mathrm{M} \Omega$. When smoke was added, the resistance decreased. A comparison of the various coatings shows that the best coatings were polyurethane, parylene, and acrylic; the worst were silicone and epoxy. In fact, the resistance of two out of the four silicone-coated boards was low during the preburn period for both SMT and PTH circuits.

The PTH circuit displayed two types of failure (Figure 7): one in which resistance decreased as in the SMT circuit and one in which it increased. Because this is a linear plot, we did not show the actual values of the circuits that were over $100 \mathrm{M} \Omega$; instead, all values greater than $100 \mathrm{M} \Omega$ were plotted at $100 \mathrm{M} \Omega$. (Some values were as great as $500 \mathrm{M} \Omega$.) This increase indicates an open circuit, which could be indicative of direct corrosive attack or a cracked solder joint. A month after the smoke exposure, the circuits were measured again and indicated 
Table 3: Coatings tested.

\begin{tabular}{lllll}
\hline \hline Coating Types & Brand & Product & $\begin{array}{c}\text { Film thickness } \\
(\mathrm{mm})\end{array}$ & How applied \\
\hline Acrylic & Humiseal & 1B-31 & 0.064 & Dipped \\
Epoxy & Envibar & UV1244 & 0.064 & Dipped \\
Parylene & Union Carbide & Type C & 0.019 & Vacuum deposited \\
Polyurethane & Conap & CE-1155 & 0.064 & Dipped \\
Silicone & Dow & $3-1765$ & 0.13 & Dipped \\
\hline \hline
\end{tabular}

no open circuit. Since a cracked solder joint may be caused by heat warping the board, we tested the PTH boards at $75^{\circ} \mathrm{C}$ (the highest temperature in the exposure chamber to which the boards were exposed) to see if increased temperatures caused the open circuit. The boards that opened during the smoke test did not open at this temperature. Of the uncoated boards, three failed in the open condition while seven failed as if the circuit shorted. The reaction of the coated boards indicates that the polyurethane, parylene, and acrylic coatings protected against the failure where the resistance of the circuit decreased, but did not protect against an open circuit. Again, the epoxy and silicone coatings did not perform as well as the other three.

\section{CONCLUSIONS}

Smoke exposure testing is not a well-developed field in terms of an environmental qualification test for equipment. The program described here has supported some of the first tests of how digital equipment will react to smoke in real time. Smoke causes intermittent failures of digital communications. These failures are probably caused by circuit bridging; the charged smoke particles act as a bridge for electrical current. Conductivity is increased both by the airborne smoke and by soot deposits. Smoke can also cause a breakdown in solder joints and increased coupling between transmission lines.

It may be difficult to design a standard test that creates a consistent, repeatable smoke environment. Smoke damage depends on the type of fuel, conditions of the fuel (stacking, temperature, humidity), the heat and ignition of the fire, ventilation of the fire, and distance between the fire and the equipment being tested. Small variations in these conditions can create very different environments. In addition, it is difficult to measure all of the environmental effects that a fire causes. Measurements such as chemical analysis of soot and gases are usually evaluated through processing at a chemical laboratory and conclusions are drawn on results from the entire test after the fire is over. For these reasons, smoke qualification testing is not expected to become a standard soon.

SNL has begun a program to determine how to include smoke in risk assessments. This program will measure the electrical characteristics of smoke, such as conductivity, as a function of smoke density and fuel. In addition to these direct current measurements, SNL will expose connectors carrying digital signals. These communications are expected to be more sensitive to momentary shorts than the direct current measurements; however, they may be a better measure of the smoke tolerance of digital equipment. Bit error rates will be recorded for those measurements.

Another area of interest is connectors because they are not conformally coated and may be the most vulnerable region of a digital system. To date, the SNL tests have protected the connectors used for the component and functional board smoke exposures. 


\section{References}

1 K. Korsah, R.L. Clark, and R.T. Wood. Functional issues and environmental qualification of digital protection systems of advanced light-water nuclear reactors. Technical Report NUREG/CR-5904, ORNL/TM-12164, Oak Ridge National Laboratory, Oak Ridge, TN, 1994.

2 Mark J. Jacobus. Screening tests of representative nuclear power plant components exposed to secondary environments created by fires. Technical Report NUREG/CR-4596, SAND860394, Sandia National Laboratories, Albuquerque, NM, 1986.

3 J.S. Patton. Fire and smoke corrosivity of structural materials. Journal of Fire Sciences, 10(4):294-322, 1992.

4 American Society for Testing and Materials. Standard Test Method for Determining the Corrosive Effect of Combustion Products Using the Cone Corrosimeter. ASTM D 5485.

5 International Electrotechnical Commission. Test on gases evolved during combustion of materials from cables - Part 1: Determination of the amount of halogen acid gas. IEC 60754-1 (1994-01).

${ }^{6}$ Deutsches Institut fur Normung. Erzeugung thermischer Zersetzungsproduckte von Werkstoffen unter Luftzufr und ihre toxikologische Prufung. DIN 53436.

7 International Standards Organization. Plastics-Smoke Generation-Determination of the corrosivity of fire effluents-Part 2: Static method. ISO 11907-2:1995.

8 J.D. Sinclair. Corrosion of electronics: The role of ionic substances. Journal of the Electrochemical Society, 135(3):89C-95C, 1988.

9 Douglas Pauls. IPC cleaning and cleanliness test program. Phase 3: Water soluble fluxes. Technical report, The Institute for Interconnecting and Packaging Electronic Circuits, Lincolnwood, IL, 1992.

10 J. Thomas Chapin, Loren M. Caudill, Pravin Gandhi, and Robert Backstrom. Leakage current smoke corrosivity testing comparison of cable and material data. In International Wire and Cable Symposium Proceedings, 174 Main Street, Eatontown, NJ 07724, 1996. International Wire and Cable Symposium.

11 Kofi Korsah, Tina J. Tanaka, and T.L. Wilson, Jr. Environmental testing of an experimental digital safety channel. Technical Report NUREG/CR-6406, ORNL/TM-13122, Oak Ridge National Laboratory, Oak Ridge, TN, 1996.

12 Tina J. Tanaka. Effect of smoke on functional circuits. Technical Report NUREG/CR-6543, SAND97-2544, Sandia National Laboratories, Albuquerque, NM, 1997.

13 Ronald L. Iman, Robert V. Burress, Dennis J. Anderson, Dennis D. Huffman, Jeffry F. Koon, Barbara M. Waller, Mahendra S. Gandhi, Thomas A. Carroll, Mark J. Shireman, Carol M. Krska, Gary A. Becka, Robin L. Sellers, David P. Carlton, Roger D. Nickell, Mark I. Siewers, Gary S. Falconbury, and Terry L. Munson. Evaluation of low-residue soldering for military and commercial applications: A report from the low-residue soldering task force. Technical Report SAND95-1060, Sandia National Laboratories, Albuquerque, NM, 1995. 


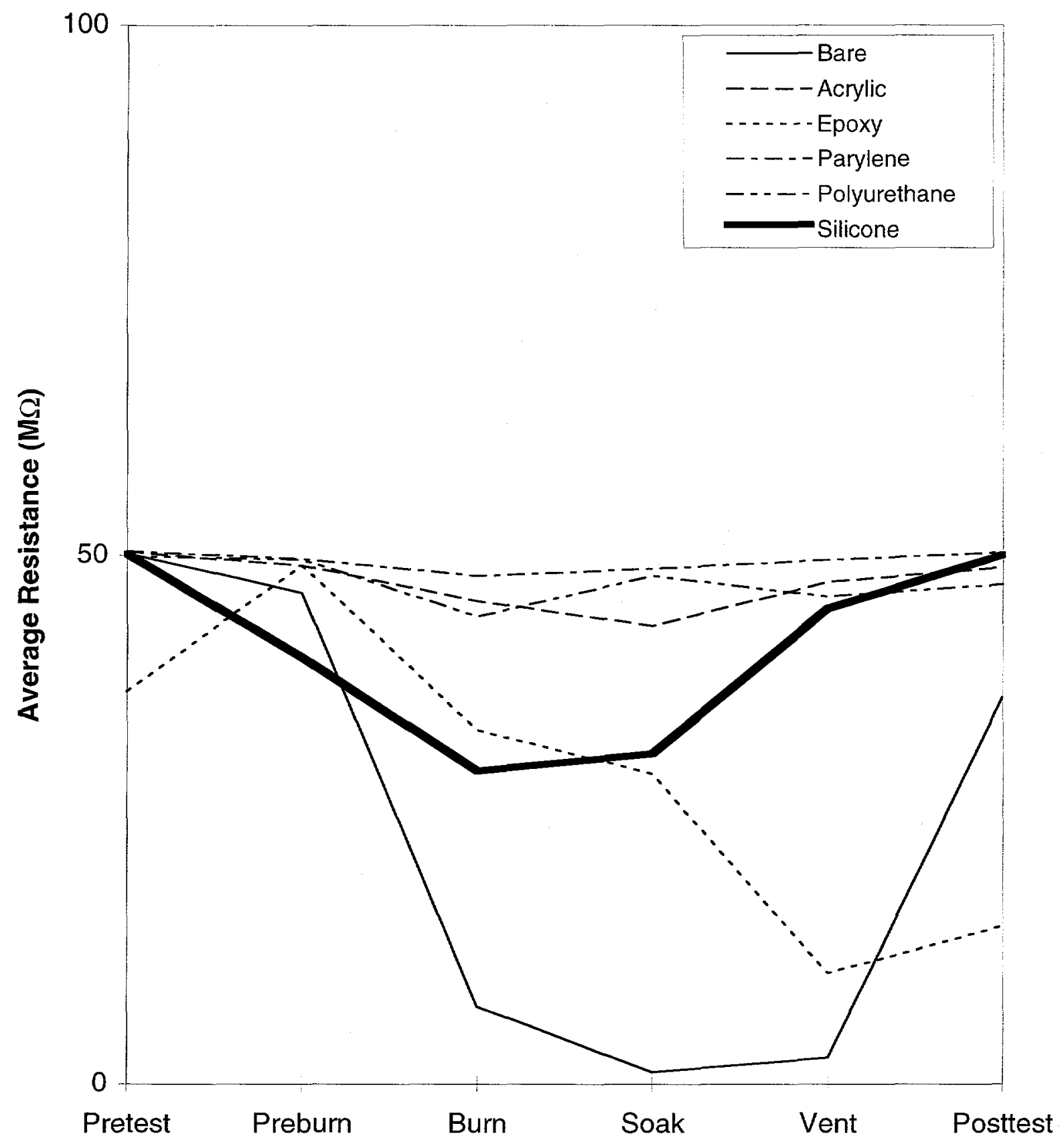

Figure 6: Coating comparison of the high-voltage, low-current circuit for the SMT components. 


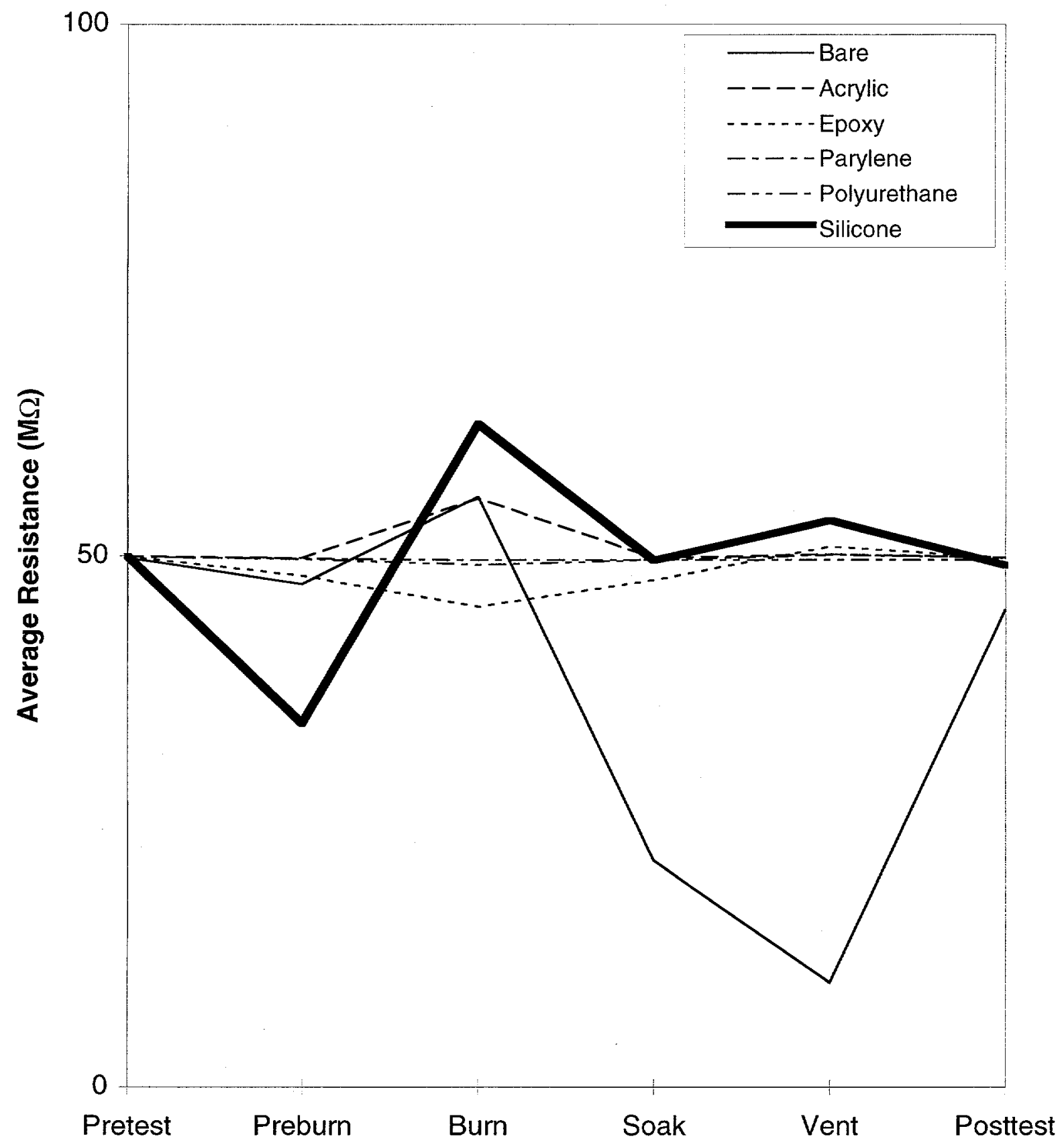

Figure 7: Coating comparison of the high-voltage, low-current circuit for the PTH components. 